\title{
Analysis and Optimization of the Effects of Meteorological Factors on 'Fuji' Fruit Quality in Two Dominant Production Regions of China
}

\author{
Qiang Zhang, Minji Li, Beibei Zhou, Junke Zhang, and Qinping Wei \\ Beijing Academy of Forestry and Pomology Sciences, Beijing Engineering \\ Research Center for Deciduous Fruit Trees, Key Laboratory of Biology and \\ Genetic Improvement of Horticultural Crops (North China), Ministry of \\ Agriculture and Rural Affairs, Beijing 100093, P.R. China
}

Additional index words. linear programming, model effect weights, multivariate analysis, partial least-squares regression

Abstract. This study aimed to understand the effects of meteorological factors on the 'Fuji' apple quality in the Circum-Bohai and Loess Plateau apple production regions of China and to guide apple production based on local climate. Fruit samples of the 'Fuji' apple and meteorological data were investigated from 132 commercial 'Fuji' apple orchards covering 44 counties in the two aforementioned production regions (22 counties per region). The partial least-squares regression (PLSR) method was first used to screen major meteorological factors that greatly affected fruit quality; these were subsequently used to establish the regression equation of fruit quality attributes and major meteorological factors. Linear programming was used to estimate optimum meteorological factors for good apple quality. The results showed that in the CircumBohai production region, many meteorological factors (total annual precipitation, total precipitation from April to October, lowest temperature from April to October, sunshine percentage from April to October) were significantly higher than those in the Loess Plateau production region; however, the temperature difference between day and night from April to October was significantly smaller than that in the Loess Plateau production region. The soluble solids content and skin color area of apples from the Loess Plateau production region were significantly greater than those from the Circum-Bohai production region. The same fruit quality factor of 'Fuji' apple was affected by different meteorological factors in the two production regions. The monthly mean temperature and monthly highest temperature from April to October of the Circum-Bohai production region had relatively larger positive effect weights on fruit quality, whereas the total annual precipitation, monthly mean relative humidity from April to October, and total precipitation from April to October of the Loess Plateau production region had relatively larger positive effect weights on fruit quality. The major influencing meteorological factors of the fruit soluble solids content were total precipitation from April to October $\left(X_{7}\right)$, mean annual temperature $\left(X_{1}\right)$, and the monthly highest temperature from April to October $\left(X_{5}\right)$ in the Circum-Bohai production region; however, it included the monthly mean temperature difference between day and night from April to October $\left(X_{6}\right)$, total annual precipitation $\left(X_{2}\right)$, and total precipitation from April to October $\left(X_{7}\right)$ in the Loess Plateau production region. In the Circum-Bohai production region, the optimum meteorological factors for 'Fuji' fruit quality of vigorous apple orchards were the mean annual temperature $\left(13.4^{\circ} \mathrm{C}\right)$, total annual precipitation $(981 \mathrm{~mm})$, monthly mean temperature $\left(16.8\right.$ to $\left.22.4^{\circ} \mathrm{C}\right)$, lowest temperature $\left(11.9^{\circ} \mathrm{C}\right.$ ), highest temperature $\left(19.5\right.$ to $\left.26.8^{\circ} \mathrm{C}\right)$, temperature difference between day and night $\left(12.3^{\circ} \mathrm{C}\right)$, total precipitation $(336-793 \mathrm{~mm})$, relative humidity $(55.7 \%$ to $70.7 \%)$, and sunshine percentage $(42.3 \%$ to $46.1 \%)$ during the growing period (April-October). In the Loess Plateau production region, the optimum meteorological factors for ' $F u j i$ ' fruit quality of vigorous apple orchards were the mean annual temperature $\left(5.5\right.$ to $\left.11.6^{\circ} \mathrm{C}\right)$, total annual precipitation $(714 \mathrm{~mm})$, monthly mean temperature $\left(13.3\right.$ to $\left.19.9^{\circ} \mathrm{C}\right)$, lowest temperature (7.9 to $\left.9.3^{\circ} \mathrm{C}\right)$, highest temperature $\left(19.6\right.$ to $\left.27.3^{\circ} \mathrm{C}\right)$, temperature difference between day and night $\left(7.1\right.$ to $\left.12.4^{\circ} \mathrm{C}\right)$, total precipitation $(338-511 \mathrm{~mm})$, relative humidity $(56.1 \%$ to $82.4 \%$ ), and sunshine percentage (37.3\% to $55.9 \%$ ) during the growing period (AprilOctober). The restrictive factors for high-quality 'Fuji' apples of the Circum-Bohai production region were the smaller monthly mean temperature difference between day and night, higher monthly mean lowest temperature, and larger monthly mean relative humidity during the growing period; however, those of the Loess Plateau production region were drought or less precipitation from November to March, lower monthly mean temperature, and higher monthly mean highest temperature during the growing period.

China has the largest apple cultivation area and highest yield in the world (Zhang et al., 2018). The Circum-Bohai and Loess Plateau production regions are the two dom- inant apple production regions, with cultivation area and yield accounting for more than $80 \%$ of the total in China. Fruit development and quality are mainly affected by meteoro- logical factors, soil nutrients, and cultivation techniques (Mattheis and Fellman, 1999), with meteorological factors playing a key role in fruit ripening and quality formation (Melke and Fetene, 2014). Due to regional differences in climatic conditions and cultivation techniques, 'Fuji' apples in the two dominant production regions differ greatly in fruit size, appearance, color, and taste (Feng et al., 2013; Ma et al., 2015; Wang et al., 2013; Zhang et al., 2017). The influence of meteorological factors on fruit quality has always been a concern because it directly affects the arrangement of apple ascendant regions. Previous studies of the relationship between meteorological factors and fruit quality mostly focused on qualitative description (Liu and $\mathrm{Pu}, 1987$; Wang and Yin, 1992; Yu et al., 1988; Yu et al., 1990) or on the correlation analysis of multiple factors, and statistical methods such as correlation analysis, path analysis, principal component regression analysis, stepwise regression, and canonical correlation analysis were involved (Wei et al., 1999a; Wei et al., 1999b; Wei et al., 2003). Previously, we combined PLSR and linear programming to analyze the relationship between comprehensive meteorological factors and 'Fuji' fruit quality (Zhang et al., 2018) and confirmed that this analysis method is feasible. The quantitative relationship of meteorological factors and the quality of 'Fuji' fruits in the two dominant production regions in China are discussed in depth to provide a theoretical basis for apple regional plantation optimization and cultivation technique adjustments based on climate.

\section{Materials and Methods}

Sampling site. The experiment was performed in 2011 and 2012. During these years, 132 orchards covering 44 advantageous apple production counties in China were chosen for the study (three orchards per county) (Table 1). Half of the orchards (66 orchards involved in 22 counties) are in Shandong, Liaoning, and Hebei provinces, namely, the Circum-Bohai production region; the other 66 orchards from another 22 counties are located in Shanxi, Shaanxi, and Gansu provinces, namely, the Loess Plateau production region. The main apple cultivar in these orchards was 15- to 20-year-old 'Fuji' grafted on crabapple (Malus pumila), free-growing spindle trees, or small canopy trees. Every orchard was larger than 0.6 ha, with loam or sandy loam soil and yielding 30,000 to $45,000 \mathrm{~kg} \cdot \mathrm{ha}^{-1} \cdot \mathrm{year}^{-1}$ for at least 5 consecutive years.

Fruit sampling and quality analysis. From the end of October to early November of 2011 and 2012, 90 fruits per orchard were picked from six trees similar in size (15 fruits per tree). The samples during these two years came from the same six trees of every orchard. Samples came from the top and outer parts of tree canopy at the southeast or southwest directions $\approx 1.5 \mathrm{~m}$ above the ground. The "just picked" samples were 
Table 1. Geographical locations of the 44 sampling counties in two apple production regions of China. ${ }^{\mathrm{z}}$

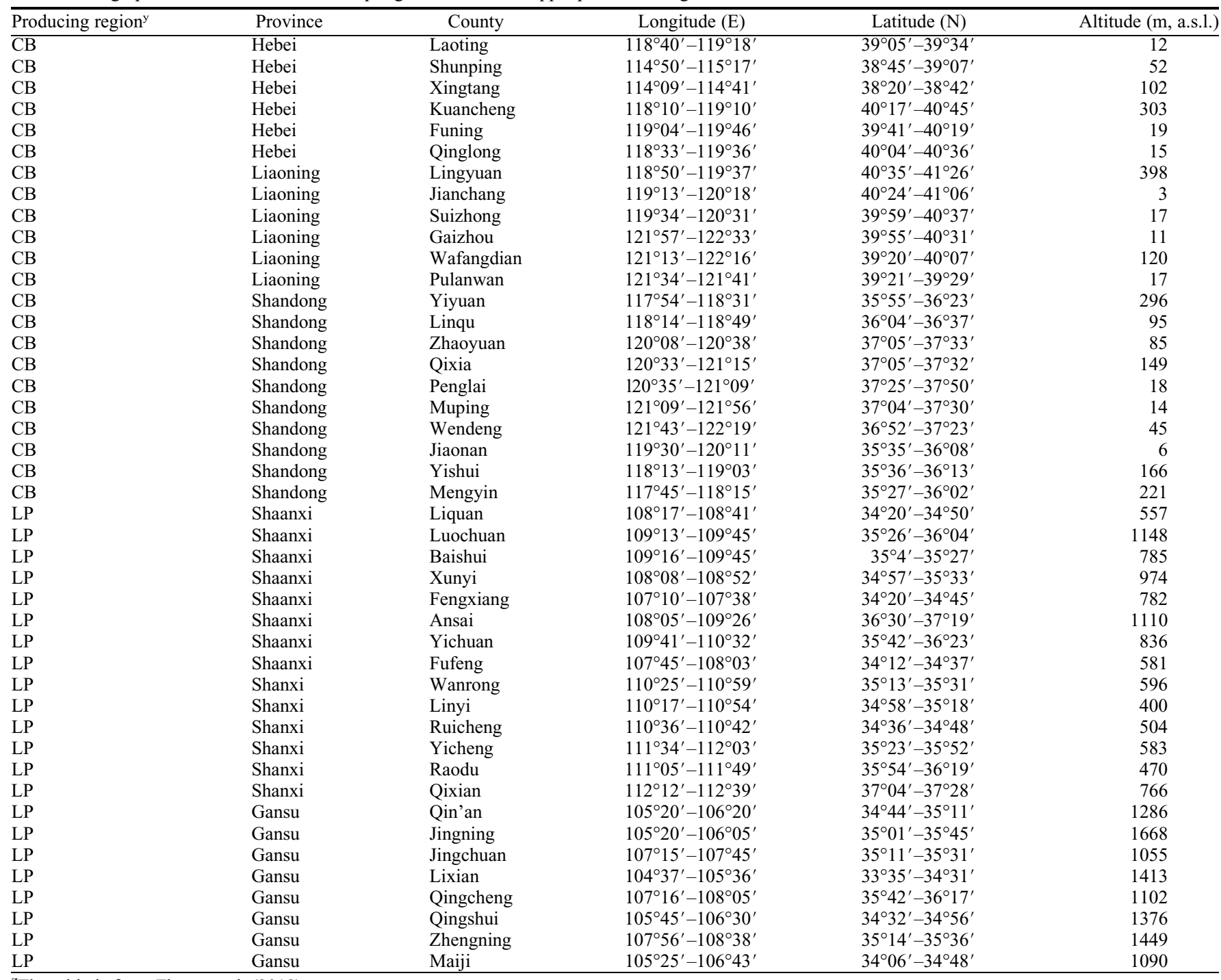

${ }^{\mathrm{z}}$ The table is from Zhang et al. (2018).

${ }^{\mathrm{y}} \mathrm{CB}$ and LP denote Circum-Bohai and Loess Plateau production regions, respectively.

placed in plastic bags and put in an insulated box filled with ice packs, immediately transferred to the laboratory in Beijing, and stored in a refrigerator at $4{ }^{\circ} \mathrm{C}$. One-third of the samples ( 30 apples per orchard) were randomly selected and the individual fruit size (length and diameter) was measured using a Vernier caliper (Harbin Measuring \& Cutting Tool Group Co., Ltd., Heilongjiang, China); then, the length/diameter (L/D) was calculated. Fruit mass was weighted using a balance with a precision of $0.001 \mathrm{~g}$. Fruit firmness

Received for publication 21 Sept. 2020. Accepted for publication 2 Nov. 2020.

Published online 8 December 2020.

This work was supported by the National Key R\&D Program of China (2019YFD1001401) and China Agriculture Research System (CARS-27).

Q.W. is the corresponding author. E-mail: qpwei@ sina.com.

This is an open access article distributed under the CC BY-NC-ND license (https://creativecommons. org/licenses/by-nc-nd/4.0/). was assessed from the opposite two sides of a fruit using a GY-1 fruit firmness tester (Mudanjiang Machinery Research Institute, Mudanjiang City, China). The soluble solids content ( $\mathrm{SSC} ;{ }^{\circ} \mathrm{Brix}$ ) was measured with a digital refractometer (Atago RS5000, Japan). The acid concentration (\%) was measured by titrating the juice with 0.1 mol. $\mathrm{L}^{-1} \mathrm{NaOH}$. The fruit skin color area was calculated according to coloring index.

Meteorological data collection. The meteorological data of 306 uniformly distributed stations near the orchards were obtained from the National Meteorological Information Center in China. The ordinary Kriging interpolation method was used to calculate the mean annual temperature, total annual precipitation, monthly mean temperature, monthly mean lowest temperature, monthly mean highest temperature, monthly mean temperature difference between day and night, total precipitation, monthly mean relative humidity, and monthly mean sunshine percentage from April to October at each orchard in 2011 and 2012.
Statistical analyses. A total of 132 orchards and related meteorological data were selected from each apple production region in 2010 and 2011. The data from these 2 years were pooled for statistical analysis. The meteorological factor and fruit quality parameters were used as independent and dependent variables, respectively, during the data analysis. First, SAS 9.4 software (SAS Institute Inc., Cary, NC) was used to perform a duplicate collinearity diagnosis of the independent variables. Second, PLSR was used to explore the model effect weights of independent variables on dependent variables; then, the independent variables that contributed less to the dependent variables were excluded according to the variable importance for projection (VIP) values, and the major meteorological factors related to fruit qualities were screened. Third, a linear regression model for the chosen meteorological factors and fruit quality was established for each apple production region, and the significance of the model was tested. Fourth, linear programming was performed using 
Table 2. Ranges of meteorological factors and fruit qualities in two apple production regions.

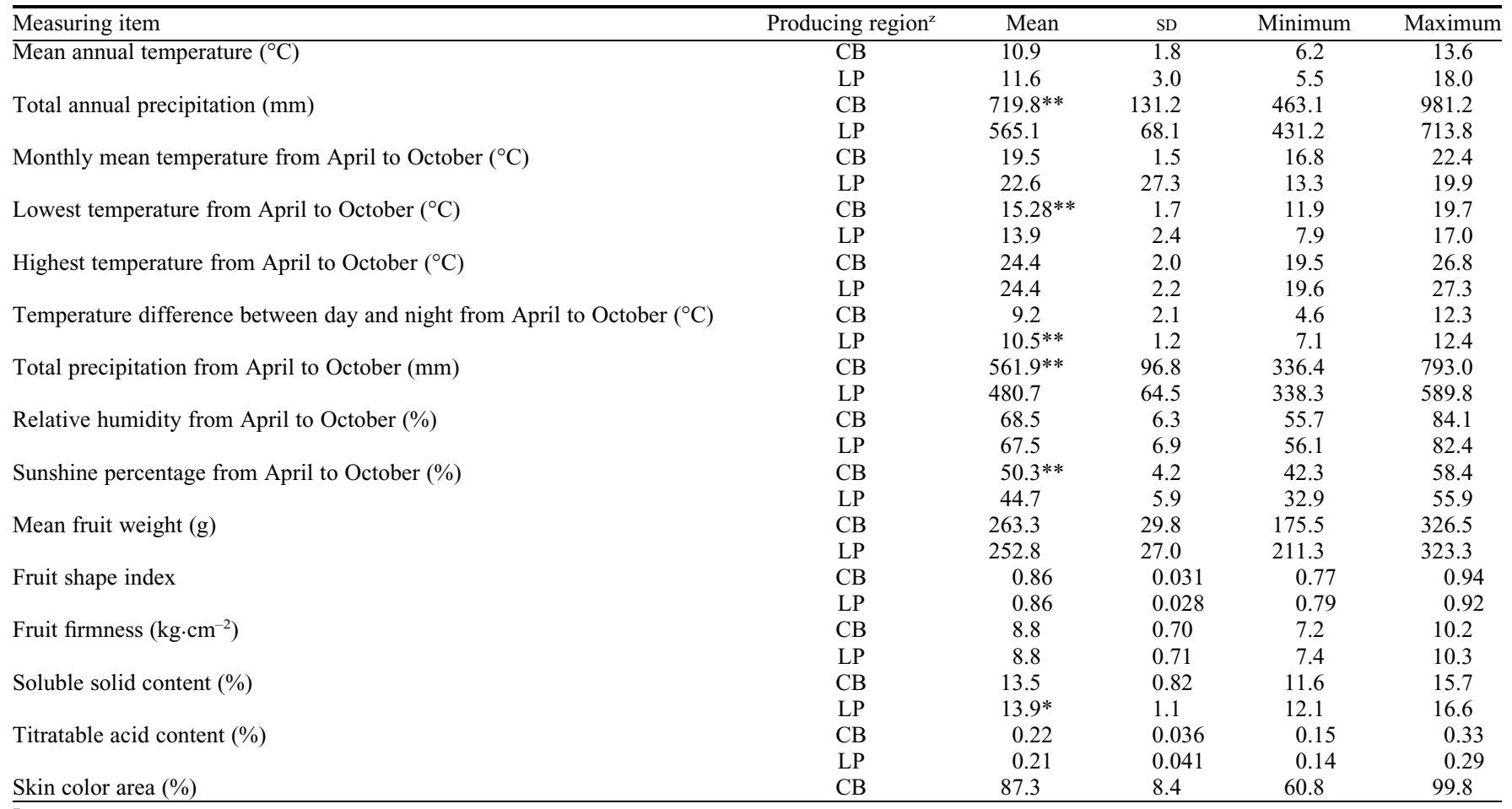

${ }^{\mathrm{z}} \mathrm{CB}$ and LP denote Circum-Bohai and Loess Plateau production regions, respectively.

$*, * *$ Significantly different at 0.05 or 0.01 levels, respectively ( $\mathrm{t}$ method).

LINGO 10.0 Software (Lindo System Inc., Chicago, IL) to determine the maximum dependent variable of a certain fruit quality under given constraint conditions (e.g., meteorological factors and other fruit quality traits). Finally, the optimum meteorological factors for high-quality 'Fuji' apple were determined.

\section{Results}

Differences in meteorological factors and fruit quality in two apple dominant production regions

The Circum-Bohai and Loess Plateau apple production regions have significantly different meteorological factors and fruit qualities (Table 2). The total annual precipitation, total precipitation from April to October, the lowest temperature from April to October, and sunshine percentage from April to October in the Circum-Bohai production region were all significantly higher than those in the Loess Plateau production region; however, the temperature difference between day and night from April to October in the Circum-Bohai production region was significantly lower than that in the Loess Plateau production region. The results indicated that there were some differences in meteorological factors between the two dominant production regions. The SSC and skin color area of fruits form the Loess Plateau production region were both significantly larger than those from the Circum-Bohai production region, which indicated that the quality of 'Fuji' fruit from the Loess Plateau production region was superior to that of fruit from the Loess Plateau production region.

\section{Selection of meteorological factors affecting fruit qualities in different production regions}

Meteorological factors weight differences in the model of meteorological factors-fruit quality attributes in two dominant production regions. The weight indicates the effect proportion assigned to each meteorological factor in the model of the relationship between fruit quality attributes and meteorological factors. PLSR was used to analyze the effect weight of every meteorological factor in the model (Fig. 1). In the
Circum-Bohai production region, the monthly mean temperature and monthly highest temperature from April to October both had relatively larger positive effect weights on fruit quality, whereas the total annual precipitation, monthly mean relative humidity from April to October, and total precipitation from April to October had relatively larger negative effect weights on fruit quality. The total annual precipitation, monthly mean relative humidity from April to October, and total precipitation from April to

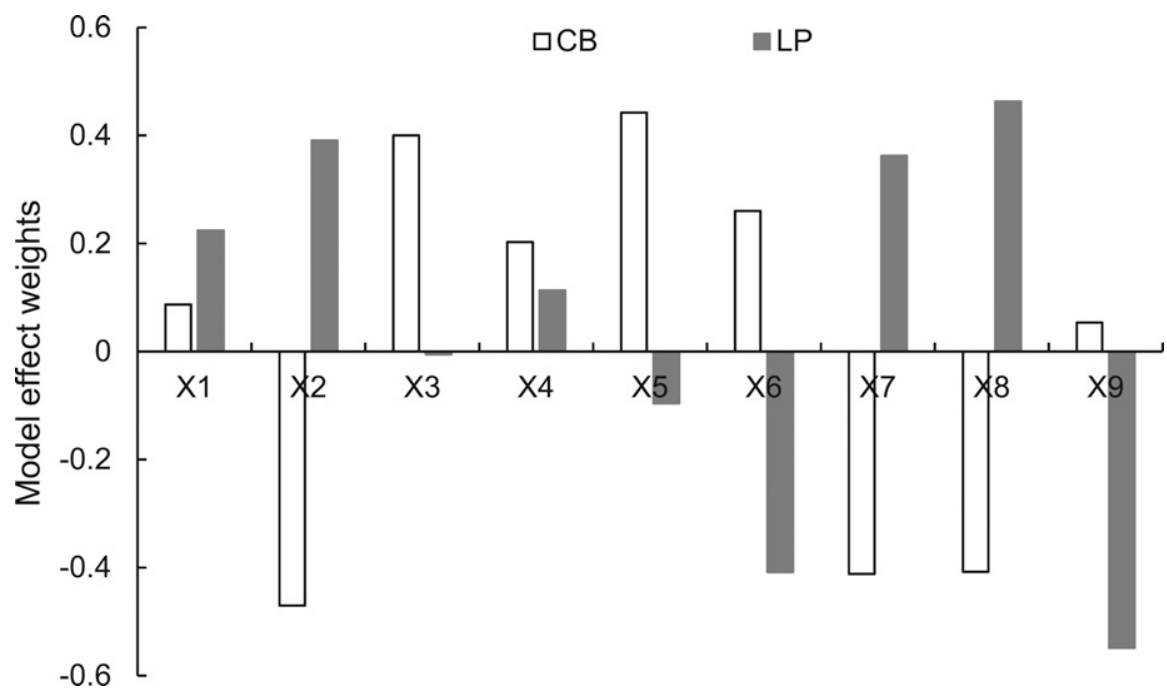

Fig. 1. Model effect weights of meteorological factors on fruit qualities in two dominant production regions of China. $X_{1}-X_{9}$ denote the mean annual temperature, total annual precipitation, monthly mean temperature from April to October, monthly mean lowest temperature from April to October, monthly mean highest temperature from April to October, monthly mean temperature difference between day and night from April to October, total precipitation from April to October, monthly mean relative humidity from April to October, and monthly mean sunshine percentage from April to October, respectively. 
October of the Loess Plateau production region had relatively larger positive effect weights on fruit quality, whereas the monthly mean sunshine percentage and temperature difference between day and night from April to October had relatively larger negative effect weights on fruit qualities. The results demonstrated that the quality of 'Fuji' apples from the two production regions was affected by meteorological factors in a different manner.

Variable projections of different meteorological factors on fruit quality attributes. To clearly show the importance of different meteorological factors on fruit quality attributes, a model is established. The model takes the mean annual temperature $\left(X_{1}\right)$, total annual precipitation $\left(X_{2}\right)$, monthly mean temperature from April to October $\left(X_{3}\right)$, monthly lowest temperature from April to October $\left(X_{4}\right)$, monthly highest temperature from April to October $\left(X_{5}\right)$, monthly mean temperature difference between day and night from April to October $\left(X_{6}\right)$, total precipitation from April to October $\left(X_{7}\right)$, monthly mean relative humidity from April to October $\left(X_{8}\right)$, and monthly mean sunshine percentage from April to October $\left(X_{9}\right)$ as independent variables, and the mean fruit weight $\left(Y_{1}\right)$, fruit shape index $\left(Y_{2}\right)$, fruit firmness $\left(Y_{3}\right), \operatorname{SSC}\left(Y_{4}\right)$, TA content $\left(Y_{5}\right)$ and skin color area $\left(Y_{6}\right)$ as dependent variables. Analytical methods of PLSR VIP (Zhou et al., 2016) were used to calculate the VIP values of the effect of every meteorological factor on fruit quality. The meteorological factor with a VIP value more than 0.8 was considered a major influencing meteorological factor of fruit quality. The results are presented in Figs. 2 and 3. The meteorological factors that had significant effects on the fruit quality were $X_{8}, X_{5}$, and $X_{4}$ for the two apple production regions. Precipitation $\left(X_{2}, X_{7}\right)$ greatly affected the fruit shape index in the Circum-Bohai production region, with the exception of the precipitation factor $\left(X_{2}\right)$; the monthly mean sunshine percentage from April to October $\left(X_{9}\right)$ had significant effects on fruit shape index in the Loess Plateau production region. The fruit firmness was affected by meteorological factors of $X_{3}$ and $X_{5}-X_{9}$ in the Circum-Bohai production region; it was affected by $X_{2}, X_{3}, X_{5}$, and $X_{7}-X_{9}$ in the Loess Plateau production region. The meteorological factors $X_{3}, X_{5}, X_{7}, X_{8}$, and $X_{9}$ were common influencing factors for fruit firmness in the two regions. The major meteorological factors related to fruit SSC were $X_{1}, X_{5}$, and $X_{7}$ in the Circum-Bohai production region; however, it was related to $X_{2}, X_{6}$, and $X_{7}$ in the Loess Plateau production region. In the Circum-Bohai production region, the fruit titratable acid (TA) content was affected by the meteorological factors of $X_{2}, X_{3}$, and $X_{9}$; however, in the Loess Plateau production region, it was influenced by $X_{6}, X_{8}$, and $X_{9} . X_{9}$ was the only common influencing factor for TA in the two apple production regions. Major influencing meteorological factors for the fruit skin color area were $X_{2}, X_{8}, X_{5}$, and $X_{6}$

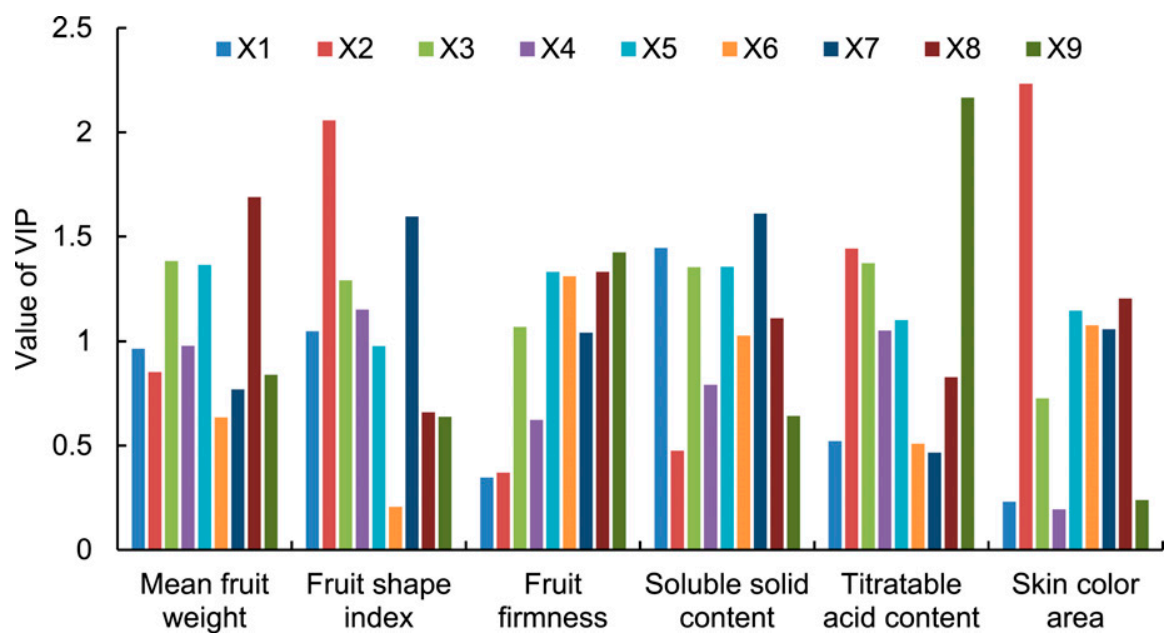

Fig. 2. Variable importance for projection (VIP) of meteorological factors affecting fruit qualities in the Circum-Bohai apple-producing region of China. $X_{1}-X_{9}$ denote the mean annual temperature, total annual precipitation, monthly mean temperature from April to October, monthly mean lowest temperature from April to October, monthly mean highest temperature from April to October, monthly mean temperature difference between day and night from April to October, total precipitation from April to October, monthly mean relative humidity from April to October, and monthly mean sunshine percentage from April to October, respectively. in the Circum-Bohai production region; however, it involved $X_{9}, X_{3}, X_{7}$, and $X_{1}$ in the Loess Plateau production region. These results indicated that the same fruit quality attributes were affected by different meteorological factors in different production regions.

\section{Schemes of optimum meteorological factors for good quality of 'Fuji' apple in two production regions}

According to Figs. 2 and 3, the meteorological factors that were strongly associated with fruit quality attributes $\left(Y_{1}-Y_{6}\right)$ were screened out for the two production regions. Then, a reliable, stable regression equation was established to estimate the effect of every major factor on fruit quality (Table 3 ). The significant levels of equation tests indicated that the established regression equations were stable and reliable. The coefficients and symbols of the regression equation indicated the importance of positive and negative effects of different meteorological factors on fruit qualities. Results showed that the mean fruit weight was significantly positively affected by $X_{3}$ and $X_{5}$ in both the Circum-Bohai and Loess Plateau production regions, but that it was negatively affected by $X_{5}$ in the Circum-Bohai region and by $X_{4}$ in Loess Plateau production region. The

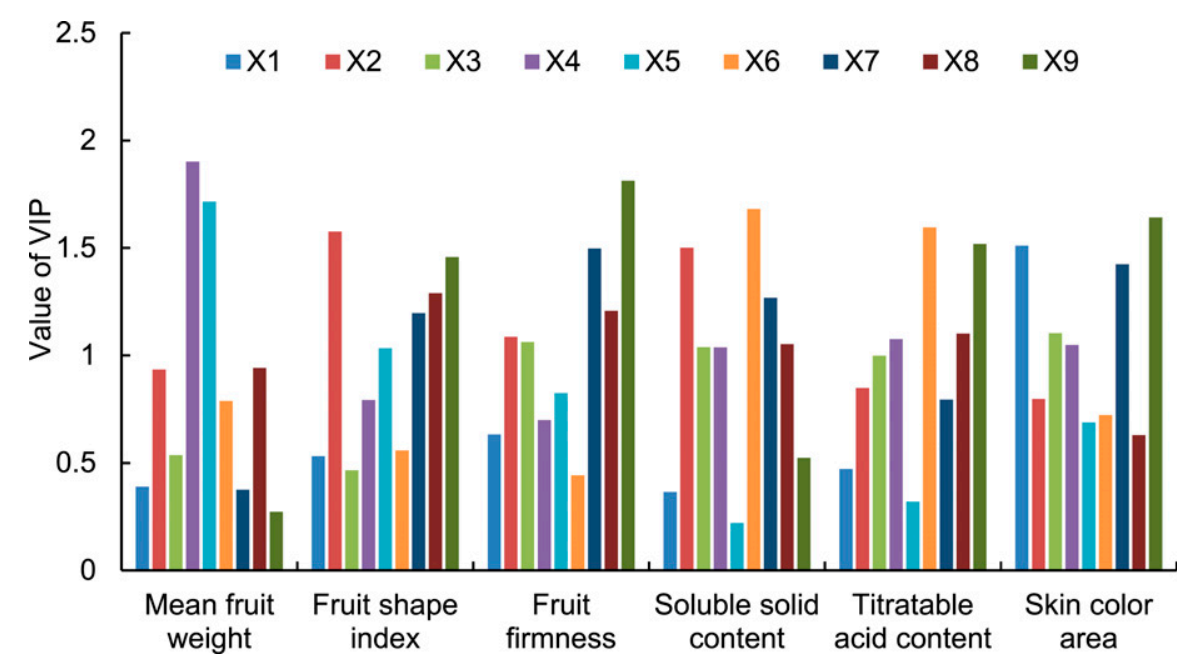

Fig. 3. Variable importance for projection (VIP) of the meteorological factors affecting fruit quality in the Loess Plateau apple-producing region of China. $X_{1}-X_{9}$ denote the mean annual temperature, total annual precipitation, monthly mean temperature from April to October, monthly mean lowest temperature from April to October, monthly mean highest temperature from April to October, monthly mean temperature difference between day and night from April to October, total precipitation from April to October, monthly mean relative humidity from April to October, and monthly mean sunshine percentage from April to October, respectively. 
Table 3. Regression equation of major influencing meteorological factors of fruit quality in two apple production regions.

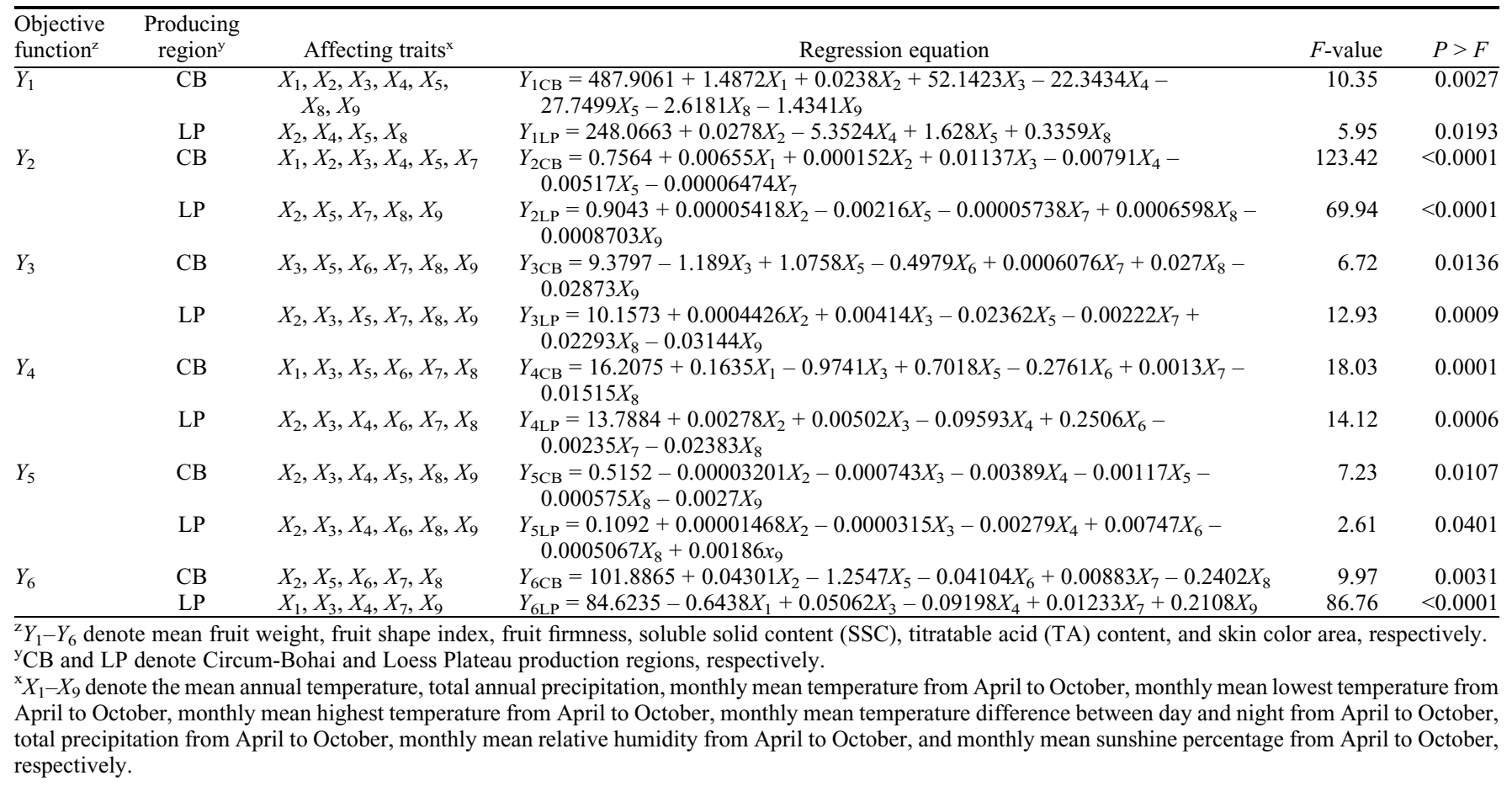

fruit shape index was significantly positively affected by $X_{3}$ and $X_{5}$ in both the Circum-Bohai and Loess Plateau production regions, but it was negatively affected by $X_{4}$ in the Circum-Bohai region and by $X_{9}$ in the Loess Plateau production region. In the Circum-Bohai production region, the fruit firmness and SSC were both positively affected by $X_{5}$ but negatively affected by $X_{3}$; the TA content was significantly negatively affected by $X_{4}$. In the Loess Plateau production region, the fruit firmness was positively affected by $X_{8}$ but negatively affected by $X_{9}$; SSC and TA content were both positively affected by $X_{6}$ but negatively affected by $X_{4}$. The fruit skin color area was significantly positively affected by $X_{2}$ and $X_{9}$ but negatively affected by $X_{5}$ and $X_{1}$ in both the Circum-Bohai and Loess Plateau production regions.

To further illustrate the effects of meteorological factors on fruit quality attributes, linear programming equations were constructed using the regression analysis in Table 3 for the two apple production regions. When maximizing a certain fruit quality attribute, the other fruit quality attributes were ensured to be optimal and each trait's restraint value was greater than the average value of that production region; furthermore, the meteorological factors were limited in a certain constraint range. Because the meteorological factors were fixed in a given year, the minimum and maximum values of a meteorological factor from 66 orchards were used as the constraint range for the apple production region. The linear programming equations for solving the largest fruit quality were established for the two apple production regions.

The linear programming Eq. [1] for maximizing the mean fruit weight in the Circum-Bohai production region $\left(Y_{1 \mathrm{CB}}\right)$ is as follows:

$$
\begin{aligned}
\operatorname{Max} Y_{1 \mathrm{CB}}= & 487.9061+1.4872 X_{1} \\
& +0.0238 X_{2}+52.1423 X_{3} \\
& -22.3434 X_{4}-27.7499 X_{5} \\
& -2.6181 X_{8}-1.4341 X_{9} ; \\
Y_{2 \mathrm{CB}}= & 0.7564+0.00655 X_{1} \\
& +0.000152 X_{2}+0.01137 X_{3} \\
& -0.00791 X_{4}-0.00517 X_{5} \\
& -0.00006474 X_{7} \geq 0.86 ; \\
Y_{3 \mathrm{CB}}= & 9.3797-1.189 X_{3} \\
& +1.0758 X_{5}-0.4979 X_{6} \\
& +0.0006076 X_{7}+0.027 X_{8} \\
& -0.02873 X_{9} \geq 8.8 ; \\
Y_{4 \mathrm{CB}}= & 16.2075+0.1635 X_{1} \\
& -0.9741 X_{3}+0.7018 X_{5} \\
& -0.2761 X_{6}+0.0013 X_{7} \\
& -0.01515 X_{8} \geq 13.5 ; \\
Y_{5 \mathrm{CB}}= & 0.5152-0.00003201 X_{2} \\
& -0.000743 X_{3}-0.00389 X_{4} \\
& -0.00117 X_{5}-0.000575 X_{8} \\
& -0.0027 X_{9} \geq 0.22 ; \\
Y_{6 \mathrm{CB}}= & 101.8865+0.04301 X_{2} \\
& -1.2547 X_{5}-0.04104 X_{6} \\
& +0.00883 X_{7}-0.2402 X_{8} \geq 87.3 ;
\end{aligned}
$$

$$
\begin{aligned}
& 6.2 \leq X_{1} \leq 13.4 ; 463 \leq X_{2} \leq 981 ; \\
& 16.8 \leq X_{3} \leq 22.4 ; 11.9 \leq X_{4} \leq 19.7 ; \\
& 19.5 \leq X_{5} \leq 26.8 ; 4.6 \leq X_{6} \leq 12.3 ; \\
& 336 \leq X_{7} \leq 793 ; 55.7 \leq X_{8} \leq 84.1 ; \\
& 42.3 \leq X_{9} \leq 58.4
\end{aligned}
$$

The linear programming Eq. [2] for maximizing the mean fruit weight in the
Loess Plateau production region $\left(Y_{1 \mathrm{LP}}\right)$ is as follows:

$$
\begin{aligned}
\operatorname{Max} Y_{1 \mathrm{LP}}= & 248.0663+0.0278 X_{2} \\
& -5.3524 X_{4}+1.628 X_{5} \\
& +0.3359 X_{8} \\
Y_{2 \mathrm{LP}}= & 0.9043+0.00005418 X_{2} \\
& -0.00216 X_{5}-0.00005738 X_{7} \\
+ & 0.0006598 X_{8}-0.0008703 X_{9} \geq 0.86 ; \\
Y_{3 \mathrm{LP}}= & 10.1573+0.0004426 X_{2} \\
& +0.00414 X_{3}-0.02362 X_{5} \\
& -0.00222 X_{7}+0.02293 X_{8} \\
& -0.03144 X_{9} \geq 8.8 ; \\
Y_{4 \mathrm{LP}}= & 13.7884+0.00278 X_{2}+0.00502 X_{3} \\
& -0.09593 X_{4}+0.2506 X_{6} \\
& -0.00235 X_{7}-0.02383 X_{8} \geq 13.9 ; \\
Y_{5 \mathrm{LP}}= & 0.1092+0.00001468 X_{2} \\
& -0.0000315 X_{3}-0.00279 X_{4} \\
& +0.00747 X_{6}-0.0005067 X_{8} \\
+ & 0.00186 X_{9} \geq 0.21 ; \\
Y_{6 \mathrm{LP}}= & 84.6235-0.6438 X_{1}+0.05062 X_{3} \\
& -0.09198 X_{4}+0.01233 X_{7} \\
+ & 0.2108 X_{9} \geq 93.4 ;
\end{aligned}
$$

$$
\begin{aligned}
5.5 & \leq X_{1} \leq 18 ; 431 \leq X_{2} \leq 714 ; \\
13.3 & \leq X_{3} \leq 19.9 ; 7.9 \leq X_{4} \leq 17 \\
19.6 & \leq X_{5} \leq 27.3 ; 7.1 \leq X_{6} \leq 12.4 \\
338 & \leq X_{7} \leq 590 ; 56.1 \leq X_{8} \leq 82.4 \\
32.9 & \leq X_{9} \leq 55.9
\end{aligned}
$$

We used the same method to solve the maximum values of other fruit quality attributes, and optimum schemes of meteorological 
factors for the largest fruit quality factor in the two apple production regions were obtained (Table 4). The results showed that the fruit quality attributes of the Circum-Bohai and Loess Plateau production regions required the maximum value of the restraint conditions for $X_{2}$ and the minimum value of the restraint conditions for $X_{4}$. In the Circum-Bohai production region, $X_{1}$ had the theoretical optimum value of $13.4{ }^{\circ} \mathrm{C}, X_{2}$ and $X_{6}$ both required the maximum value of the restraint conditions $\left(981 \mathrm{~mm}\right.$ and $12.3{ }^{\circ} \mathrm{C}$ ), and $X_{4}$ required the minimum value of the restraint conditions $\left(11.9{ }^{\circ} \mathrm{C}\right)$. This indicated that the meteorological factors for high-quality fruit in the Circum-Bohai production region were mean annual temperature $\left(13.4{ }^{\circ} \mathrm{C}\right)$, abundant precipitation, large temperature difference between day and night, and relatively low minimum temperature at the fruit ripening stage. Furthermore, the theoretical optimum values of $X_{8}$ and $X_{9}$ were lower than the measured maximum value, which indicated that suitable relative humidity $(55.7 \%$ to $70.7 \%)$ and sunshine percentage $(42.3 \%$ to $46.1 \%$ ) during the growing period (from April to October) were also important influencing factors for the fruit quality in the CircumBohai production region. The optimum meteorological factors for high-quality fruit of the Circum-Bohai production region were mean annual temperature $\left(13.4{ }^{\circ} \mathrm{C}\right)$, total annual precipitation $(981 \mathrm{~mm})$, and total precipitation from April to October (between 336 and $793 \mathrm{~mm}$ ). The monthly mean temperature, lowest temperature, highest temperature, temperature difference between day and night, relative humidity and sunshine percentage from April to October were 16.8 to $22.4{ }^{\circ} \mathrm{C}, 11.9{ }^{\circ} \mathrm{C}, 19.5$ to $26.8^{\circ} \mathrm{C}, 12.3{ }^{\circ} \mathrm{C}$, $55.7 \%$ to $70.7 \%$, and $42.3 \%$ to $46.1 \%$, respectively. In the Loess Plateau production region, the theoretical optimum value of $X_{2}$ required the maximum value of the restraint conditions $(714 \mathrm{~mm})$, and the theoretical optimum value of $X_{7}$ was lower than the actual measured maximum $(590 \mathrm{~mm})$. Fruit quality attributes except for fruit skin color area $(511 \mathrm{~mm})$ had a selected the minimum constraint value of $X_{7}(338 \mathrm{~mm})$. Except for mean fruit weight, the other fruit quality attributes selected were the maximum constraint value of $X_{3}\left(19.9^{\circ} \mathrm{C}\right)$ and the minimum constraint value of $X_{5}\left(19.6{ }^{\circ} \mathrm{C}\right)$. The results indicated that high-quality 'Fuji' apples can be produced in regions with intensive precipitation in winter and early spring, relatively higher monthly mean temperatures, and low monthly mean maximum temperatures from April to October in the Loess Plateau production region. Moreover, the theoretical optimum values of $X_{1}$ and $X_{4}$ were lower than the maximum measured value, which indicated that a suitable mean annual temperature (5.5 to $11.6^{\circ} \mathrm{C}$ ) and monthly mean lowest temperature from April to October $\left(7.9\right.$ to $\left.9.3^{\circ} \mathrm{C}\right)$ were also important influencing factors for fruit quality in the Loess Plateau production region. The optimum meteorological factors for high-quality fruit in the Loess Plateau production region were mean annual temperature $\left(5.5\right.$ to $\left.11.6^{\circ} \mathrm{C}\right)$, total annual precipitation $(714 \mathrm{~mm})$, and total precipitation from April to October (338 to $511 \mathrm{~mm}$ ). The monthly mean temperature, lowest temperature, highest temperature, temperature difference between day and night, relative humidity and sunshine percentage from April to October were 13.3 to $19.9{ }^{\circ} \mathrm{C}, 7.9$ to $9.3{ }^{\circ} \mathrm{C}, 19.6$ to $27.3{ }^{\circ} \mathrm{C}, 7.1$ to $12.4{ }^{\circ} \mathrm{C}, 56.1 \%$ to $82.4 \%$, and $37.3 \%$ to $55.9 \%$, respectively.

\section{Discussion}

\section{Optimum schemes of meteorological factors for fruit quality attributes in the two production regions}

Apple fruit quality was a comprehensive reflection of the climatic and environmental factors, such as temperature, light, precipitation, and relative humidity (Wang and Yin, 1992). This study found that the same fruit quality attributes of 'Fuji apples' from the two regions were affected by meteorological factors in a different manner, even in the opposite way, consistent with the results of Wei et al. (1999b) and Duan et al. (2014).

Temperature-related factors during the apple growing period, monthly mean temperature, and the highest temperature had large positive effect weights on fruit quality in the Circum-Bohai production region. In the study performed by Sugiura et al. (2013), a similar result was obtained; namely, the climate change had effects on the flavor and texture changes of 'Fuji' and 'Tsugaru' apples of Nagano and Aomori. This may be due to the temperature during the growing season, which directly affected the flowering and maturity period of apple. Furthermore, fruit firmness and SSC of apples from the CircumBohai production region were significantly positively affected by the highest temperature from April to October, but they were significantly negatively affected by the monthly mean temperature from April to October, which was consistent with the results based on citrus studied by Bao et al. (2004). The TA content of fruits from the two production regions were greatly negatively affected by the monthly mean lowest temperature from April to October, which was consistent with the results of $\mathrm{Yu}$ and $\mathrm{Pu}$ (1991) and Zhou et al. (2002). Reductions in the acid concentration and sugar metabolism in the fruit are apparently greatly affected by temperature (Takashi and Hisashi, 1988). It can be speculated that the increase of the lowest temperature from April to October prolonged the growth period of the 'Fuji' apple and then affected the metabolism of fruit sugar and acid.

Table 4. Optimum schemes of meteorological factors for the largest fruit quality factor in two apple production regions.

\begin{tabular}{|c|c|c|c|c|c|c|c|c|}
\hline Objective function $^{z}$ & Producing region $^{\mathrm{y}}$ & $Y_{1}(\mathrm{~g})^{\mathrm{x}}$ & $Y_{2}$ & $Y_{3}\left(\mathrm{~kg} \cdot \mathrm{cm}^{-2}\right)$ & $Y_{4}(\%)$ & $Y_{5}(\%)$ & $Y_{6}(\%)$ & Range of objective function \\
\hline \multirow{2}{*}{$\overline{X_{1}\left({ }^{\circ} \mathrm{C}\right)}$} & $\mathrm{CB}$ & 13.4 & 13.4 & 13.4 & 13.4 & 13.4 & 13.4 & 13.4 \\
\hline & LP & 5.5 & 5.5 & 5.5 & 5.5 & 11.6 & 5.5 & $5.5-11.6$ \\
\hline \multirow[t]{2}{*}{$X_{2}(\mathrm{~mm})$} & $\mathrm{CB}$ & 981 & 981 & 981 & 981 & 981 & 981 & 981 \\
\hline & LP & 714 & 714 & 714 & 714 & 714 & 714 & 714 \\
\hline \multirow[t]{2}{*}{$X_{3}\left({ }^{\circ} \mathrm{C}\right)$} & $\mathrm{CB}$ & 22.4 & 22.4 & 18.3 & 18.3 & 16.8 & 16.8 & $16.8-22.4$ \\
\hline & LP & 13.3 & 19.9 & 19.9 & 19.9 & 19.9 & 19.9 & $13.3-19.9$ \\
\hline \multirow{2}{*}{$X_{4}\left({ }^{\circ} \mathrm{C}\right)$} & $\mathrm{CB}$ & 11.9 & 11.9 & 11.9 & 11.9 & 11.9 & 11.9 & 11.9 \\
\hline & LP & 7.9 & 7.9 & 7.9 & 7.9 & 7.9 & 9.3 & $7.9-9.3$ \\
\hline \multirow[t]{2}{*}{$X_{5}\left({ }^{\circ} \mathrm{C}\right)$} & $\mathrm{CB}$ & 25.7 & 26.5 & 26.8 & 26.8 & 19.5 & 19.5 & $19.5-26.8$ \\
\hline & LP & 27.3 & 19.6 & 19.6 & 19.6 & 19.6 & 19.6 & $19.6-27.3$ \\
\hline \multirow[t]{2}{*}{$X_{6}\left({ }^{\circ} \mathrm{C}\right)$} & $\mathrm{CB}$ & 12.3 & 12.3 & 12.3 & 12.3 & 12.3 & 12.3 & 12.3 \\
\hline & LP & 7.1 & 12.4 & 12.4 & 12.4 & 8.6 & 7.1 & $7.1-12.4$ \\
\hline \multirow[t]{2}{*}{$X_{7}(\mathrm{~mm})$} & $\mathrm{CB}$ & 793 & 336 & 793 & 793 & 336 & 793 & $336-793$ \\
\hline & LP & 338 & 338 & 338 & 338 & 338 & 511 & $338-511$ \\
\hline \multirow[t]{2}{*}{$X_{8}(\%)$} & $\mathrm{CB}$ & 55.7 & 55.7 & 55.7 & 55.7 & 70.7 & 55.7 & $55.7-70.7$ \\
\hline & LP & 82.4 & 82.4 & 82.4 & 56.1 & 56.1 & 69.8 & $56.1-82.4$ \\
\hline \multirow{2}{*}{$X_{9}(\%)$} & CB & 46.1 & 46.1 & 46.1 & 46.1 & 42.3 & 46.1 & $42.3-46.1$ \\
\hline & LP & 54.6 & 37.3 & 37.3 & 37.3 & 55.9 & 55.9 & $37.3-55.9$ \\
\hline \multirow{2}{*}{$\begin{array}{l}\text { Objective value of } \\
\text { fruit qualities }\left(Y_{\mathrm{n}}\right)\end{array}$} & $\mathrm{CB}$ & 507.6 & 0.99 & 14.9 & 18.4 & 0.25 & 112.9 & - \\
\hline & LP & 297.8 & 0.90 & 10.1 & 16.1 & 0.24 & 99.3 & - \\
\hline
\end{tabular}

${ }^{{ }^{z}} X_{1}-X_{9}$ denote the mean annual temperature, total annual precipitation, monthly mean temperature from April to October, monthly mean lowest temperature from April to October, monthly mean highest temperature from April to October, monthly mean temperature difference between day and night from April to October, total precipitation from April to October, monthly mean relative humidity from April to October, and monthly mean sunshine percentage from April to October, respectively.

${ }^{\mathrm{y}} \mathrm{CB}$ and LP denote Circum-Bohai and Loess Plateau production regions, respectively.

${ }^{\mathrm{x}} Y_{1}-Y_{6}$ denote mean fruit weight, fruit shape index, fruit firmness, soluble solid content (SSC), titratable acid (TA) content, and skin color area, respectively. 
In addition to temperature, light intensity, quality, precipitation, and relative humidity influence fruit size, taste, and volatile emissions of apples (Armelle et al., 2005; Lachapelle et al., 2013). Our results showed that the fruit skin color of apples from the two production regions were significantly affected by the total precipitation during the growth period. In addition to the total precipitation during the growing period, the major meteorological factors associated with fruit skin color area were totally different between the two production regions. The fruit skin color in the Loess Plateau production region was mainly affected by mean annual temperature, monthly mean temperature from April to October, lowest temperature from April to October, and sunshine percentage from April to October; however, it was first found to be mainly affected by the total annual precipitation, highest temperature from April to October, temperature difference between day and night from April to October, and relative humidity from April to October in the Circum-Bohai production region. Furthermore, in the Loess Plateau production region, the total annual precipitation, monthly mean relative humidity from April to October, and total precipitation from April to October had relatively greater positive effect weights on fruit quality, and it was first reported that monthly mean sunshine percentage and temperature difference between day and night in growing period had greatly negative effect weights on fruit quality. In the Loess Plateau production region, fruit firmness was greatly affected by the relative humidity and sunshine percentage from April to October. SSC was significantly influenced by the temperature difference between day and night and the lowest temperature from April to October. These results were consistent with the results of Sun et al. (2009) and Zhang et al. (2018).

The meteorological factors significantly associated with fruit firmness, SSC, and TA are different between the two apple production regions. The meteorological factors that are closely related to the fruit shape index and fruit skin color area are identical in the two regions, but the positive and negative effects are opposite. These findings do not correspond with previous research results, which may be due to the different statistical analysis methods used in studies. In the present study, the partial least-squares regression was used to select variables based on VIP values, thus eliminating the interference of human factors and the complex collinearity among multiple independent variable factors.

In addition, the partial least-squares regression was performed to establish a regression equation and then combined with linear programming to obtain the theoretical optimum schemes of meteorological factors for the largest fruit quality attribute in each of the two apple production regions. The optimum mean annual temperatures for high-quality 'Fuji' apples were $13.4^{\circ} \mathrm{C}$ and 5.5 to $11.6^{\circ} \mathrm{C}$ in the Circum-Bohai and Loess Plateau regions, respectively. The optimum mean annual temperatures were both consistent with some reported by previous stud- ies (Liu and Mao, 2001; Lu, 1980; Qu and Zhou, 2016; Shou, 1990; Zhu et al.; 2001). The optimal total annual precipitations for high-quality 'Fuji' apples were $981 \mathrm{~mm}$ and $714 \mathrm{~mm}$ in the Circum-Bohai region and Loess Plateau regions, respectively; these were higher than the results reported Liu and Mao (2001) and Wei et al. (2003). The lower limit $\left(16.8^{\circ} \mathrm{C}\right)$ of the optimal monthly mean temperature from April to October in the Circum-Bohai production region was close to that $\left(16.2{ }^{\circ} \mathrm{C}\right)$ reported by $\mathrm{Qu}$ et al. (2008). However, the upper limit $\left(19.9^{\circ} \mathrm{C}\right)$ of the optimal value of the monthly mean temperature from April to October in the Loess Plateau production region was close to the results $\left(19.7{ }^{\circ} \mathrm{C}\right)$ reported by $\mathrm{Qu}$ et al. (2008). The temperature of $12.3^{\circ} \mathrm{C}$ was the optimal monthly mean temperature difference between day and night from April to October for high-quality 'Fuji' apples from the Circum-Bohai region, which was higher than those reported by previous studies (Gao et al., 2009; Wei et al., 2003; Zhu et al., 2001). In our study, we found that the upper limit of monthly mean relative humidity from April to October was $82.4 \%$ for highquality (mean fruit weight, fruit shape index, and firmness) 'Fuji' apples of the Loess Plateau region, which was significantly higher than the result of $\leq 70 \%$ reported by Li et al. (2000).

\section{Restrictive meteorological factors and countermeasures for high-quality apple in the two production regions}

Ecological factors play a key role in the formation of apple fruit quality; therefore, it is the fundamental basis for the formulation of apple production regions division and cultivation management measures $(\mathrm{Qu}$ and Chen, 1988). Optimum schemes of meteorological factors for good fruit quality were quite different for the two production regions in our study. In the Circum-Bohai production region, the proposed optimum meteorological factors for high-quality 'Fuji' apples were the mean annual temperature $\left(13.4{ }^{\circ} \mathrm{C}\right)$ and total annual precipitation. Furthermore, the monthly mean temperature difference between day and night from April to October required the highest values of the constraint condition $\left(981 \mathrm{~mm}\right.$ and $\left.12.3{ }^{\circ} \mathrm{C}\right)$, and the monthly mean lowest temperature from April to October required the lowest value of the constraint condition $\left(11.9^{\circ} \mathrm{C}\right)$. Moreover, the optimum ranges of the monthly mean relative humidity and sunshine percentage from April to October were $55.7 \%$ to $70.7 \%$ and $42.3 \%$ to $46.1 \%$, respectively; the upper limit values were both lower than the actual measured maximum value. In the Loess Plateau production region, the proposed optimum meteorological factors for high-quality 'Fuji' apples were the total annual precipitation, which required the highest value of the constraint condition $(714 \mathrm{~mm})$, the total precipitation from April to October, which required the lowest value of the constraint condition $(338 \mathrm{~mm})$ except for fruit skin color area, the monthly mean and mean highest temperature from April to October, which required the highest $\left(19.9^{\circ} \mathrm{C}\right)$ and lowest $\left(19.6{ }^{\circ} \mathrm{C}\right)$ values of the constraint condition except for mean fruit weight. Moreover, the optimum values of the mean annual temperature and monthly mean lowest temperature from April to October were 5.5 to $11.6{ }^{\circ} \mathrm{C}$ and 7.9 to $9.3{ }^{\circ} \mathrm{C}$, respectively. The optimal value of the monthly mean relative humidity, monthly mean sunshine percentage, mean annual temperature, and monthly mean lowest temperature from April to October were all lower than the actual measured maximum value.

The difference between the measured value and the theoretical value indicated that the restrictive factors of high-quality 'Fuji' apples in the Circum-Bohai production region were smaller monthly mean temperature differences between day and night, higher monthly mean lowest temperature, and larger monthly mean relative humidity during the growing period. The restrictive factors for high-quality 'Fuji' apples in the Loess Plateau production region were drought or less precipitation from November to March, lower monthly mean temperature, and higher monthly mean highest temperature during the growing period. Based on the results, the cultivation and management measures were used to improve the microclimate factors of the orchard in response to the restrictive meteorological factors in the two production regions. For instance, in the Circum-Bohai production region, reflective film mulching was laid on orchard ground during the fruit ripening stage to increase the daytime temperature, reduce the nighttime temperature, and expand the temperature difference between the day and night, which was beneficial to the accumulation of fruit sugar. Reflection of light into the internal canopy increased the photosynthetic efficiency of the lower leaves in the canopy and improved color development. Pruning was performed during the fruit-growing period, which ensured ventilation and light transmission of the canopy and improved photosynthesis of leaves, anthocyanins synthesis, and fruit coloring. Another important function of pruning was to reduce the relative humidity of the orchard. In the Loess Plateau production region, the irrigable orchards should be irrigated even from November to March of the following year, and the rain-fed orchards could keep soil water through the soil covering.

It should be pointed out that the formation of apple quality is a complex, systematic process. It is affected by not only meteorological factors (light, temperature, temperature difference between day and night, and relative humidity) but also nonclimatic factors (soil types, fertility levels, and cultivation techniques), and even the interactions among these factors (Melke and Fetene, 2014; Warrington et al., 1999). This study only focused on the effect of major meteorological factors on apple fruit quality. The other factors need to be studied further.

\section{Conclusions}

The same fruit quality attribute of 'Fuji' apple was affected by different meteorological factors in the two production regions of 
China. The meteorological factors of two production regions had varying degrees of influence on fruit quality attributes of 'Fuji' apples. The restrictive factors of high-quality 'Fuji' apples in the Circum-Bohai production region were narrower monthly mean temperature difference between day and night, higher monthly mean lowest temperature, and higher monthly mean relative humidity during the growing period, whereas the restrictive factors in the Loess Plateau production region were drought or less precipitation from November to March, lower monthly mean temperature, and higher monthly mean highest temperature during the growing period.

\section{Literature Cited}

Armelle, V., G. Hainan, and D. Silvia. 2005. How rainfall, relative humidity and temperature influence volatile emissions from apple trees in situ. Phytochemistry 66:1540-1550, doi: 10.1016/j.phytochem.2005.04.038.

Bao, J.F., R.X. Xia, and S.A. Peng. 2004. Effect of ecological factors on citrus fruit quality. J. Appl. Ecol. 15:1477-1480, doi: 10.3321/ j.issn:1001-9332.2004.08.036.

Duan, X.F., L. Zhang, F. Jin, J.G. Wei, and H.J. Du. 2014. Research progress of effects of meteorological factors on apple yield and quality. Chinese Agr. Sci. Bul. 30:33-37, doi: 10.11924/ j.issn.1000-6850.2013-1761.

Feng, J., X.L. Ren, J.W. Tian, L. Fan, and X.F. Wang. 2013. Analysis and comparison of Fuji apple quality from different regions. Sci. Technol. Food Ind. 34:108-112, doi: 10.13386/ j.issn1002-0306.2013.14.008.

Gao, H., H.K. Fan, Y.M. Lu, Y.Z. Wan, L.C. Wang, and Z.Y. Zhao. 2009. Relationship between fruit quality of 'Pink Lady' apple and meteorological factors in Chinese Weibei Highland areas. J. Northwest Sci-Tech Univ. Agr. For. (Nat. Sci. Ed.) 37:97-101, doi: 10.13207/j.cnki.jnwafu.2009.11.028.

Lachapelle, M., B. Gaétan, D. Jennifer, A.S. Katrine, and S. Philippe. 2013. Modeling the effect of preharvest weather conditions on the incidence of soft scald in 'Honeycrisp' apples. Postharvest Biol. Technol. 85:57-66, doi: 10.1016/j.postharvbio.2013.04.004.

Li, X.J., G.L. Zhang, and R.S. Liu. 2000. Ecological effect on the colored formation in apple fruit by ecologic factors. J. Fruit Sci. 17:147150, doi: 10.13925/j.cnki.gsxb.2000.02.016.

Liu, C.S. and Y.Y. Pu. 1987. Studies on the relationship between apple fruit quality of 'delicious' strain and meteorological conditions. Acta Hort. Sin. 14:73-80.

Liu, H.R. and W.Y. Mao. 2001. Analysis of Red-Fuji apple's growing climatic resource and its developmental measures in Akesu area.
Bimonthly Xinjiang Meteorol. 24:26-28, doi: 10.3969/j.issn.1002-0799.2001.04.012.

Lu, Q.N. 1980. The distribution and ecologic factors of apples in China. Sci. Agr. Sin. 13:46-51. $<$ http://www.chinaagrisci.com/CN/Y1980/ V13/I01/46>.

Ma, Y.J., J.J. Zhao, H. Deng, Y.H. Meng, and Y.R. Guo. 2015. Construction of comprehensive quality evaluation and grading system for fresh Fuji apple in Luochuan, Shaanxi. Food Sci. 36:69-74, doi: 10.7506/spkx1002-6630-201501013.

Mattheis, J.P. and J.K. Fellman. 1999. Preharvest factors influencing flavor of fresh fruit and vegetables. Postharvest Biol. Technol. 15:227232, doi: 10.1016/S0925-5214(98)00087-8.

Melke, A. and M. Fetene. 2014. Apples (Malus domestica, Borkh.) phenology in Ethiopian Highlands: Plant growth, blooming, fruit development and fruit quality perspectives. Amer. J. Exp. Agr. 4:1958-1995, doi: 10.9734/AJEA/ 2014/9783.

Qu, Z.J. and G.S. Zhou. 2016. Climate suitability for potential Fuji apple cultivation in China. Acta Meteorol. Sin. 74:479-490, doi: 10.11676/ qxxb2016.027.

Qu, Z.J., X.H. Zheng, and K. Jia. 2008. Study on the adaptability of apple to climate ecology on the Weibei rainfed tableland of the Loess Plateau, China. J. Shaanxi Agr. Sci. 2:28-31, doi: 10.3969/j.issn.0488-5368.2008.02.013.

Qu, Z.Z. and S.W. Chen. 1988. Fruit tree ecology. Shanghai Sci. Tech. Publ., Shanghai.

Shou, B.H. 1990. Agroclimateology of the major fruit production in China: A review of current practice. Agr. For. Meteorol. 53:125-142, doi: 10.1016/0168-1923(90)90128-S.

Sugiura, T., H. Ogawa, N. Fukuda, and T. Moriguchi. 2013. Changes in the taste and textural attributes of apples in response to climate change. Sci. Rep. 3:1-8, doi: 10.1038/srep02418.

Sun, Z.H., Z.C. Liu, X.M. Cao, and Y.P. Lei. 2009. Variation characteristics of main meteorological restricting factors for apple production in northern Yanan. Meteorol. Sci. Technol. 37:52-56, doi: 10.19517/j.1671-6345.2009. 01.011 .

Takashi, T. and Y. Hisashi. 1988. Relationship between temperature and fruit quality of apple cultivars grown at different locations. J. Jpn. Soc. Hort. Sci. 56:391-397, doi: 10.2503/ jjshs.56.391.

Wang, L. and S.M. Yin. 1992. An analysis on the effect of meteorological conditions on apple quality. Chinese J. Agrometeorol. 13:13-18. http://zgnyqx.ieda.org.cn/CN/Y1992/V13/I04/15.

Wang, X., J.F. Bi, X. Liu, J. Lü, and A.J. Yang. 2013. Different origin Fuji apple quality evaluation factors choice. Acta Agr. Nucl. Sin. 27: 1501-1510, doi: 10.11869/hnxb.2013.10.1501.

Warrington, I.J., T.A. Fulton, E.A. Halligan, and H.N. De Silva. 1999. Apple fruit growth and maturity are affected by early season tempera- ture. J. Amer. Soc. Hort. Sci. 124:468-477, doi: 10.1023/A:1008783705183.

Wei, Q.P., J.R. Li, and S.H. Cheng. 1999a. Relationships between fruit quality and meteorological factors in 'Jonagold' apples. J. Shandong Agr. Univ. 30:436-440, doi: 10.3969/j.issn.10002324.1999.04.025

Wei, Q.P., S.H. Cheng, F. Tang, J.R. Li, and D.L. Zhang. 1999b. Relationship between fruit quality of Fuji apple and meteorological factors. Chinese J. Appl. Ecol. 10:289-292, doi: 10.3321/j.issn:1001-9332.1999.03.009.

Wei, Q.P., J.X. Zhang, Z.Q. Mao, and J.R. Li. 2003. Optimum meteorological factors and climate divisions of apple for good quality. Chinese $\mathrm{J}$. Appl. Ecol. 14:713-716, doi: 10.3321/j.issn: 1001-9332.2003.05.014.

Yu, Y.S., B.J. Ge, and Y.Y. Pu. 1990. Study on the relationship between apple fruit soluble solid content and temperature. Chinese J. Agrometeorol. 11:34-38. http://zgnyqx.ieda.org.cn/CN/ Y1990/V11/I03/34.

Yu, Y.S. and Y.Y. Pu. 1991. A study on the relationship between the quality of apple and meteorological conditions. Meteorol. Monthly 17:22-26, doi: 10.7519/j.issn.1000-0526.1991.03.004.

Yu, Y.S., Y.Y. Pu, and R.N. Lin. 1988. Climatic belt analysis about the high quality of apple in the north Weihe River among the Loess Plateau. J. Nat. Resour. 3:312-322, doi: 10.11849/ zrzyxb.1988.04.003.

Zhang, Q., B.B. Zhou, M.J. Li, Q.P. Wei, and Z.H. Han. 2018. Multivariate analysis between meteorological factor and fruit quality of Fuji apple at different locations in China. J. Integr. Agr. 17:1338-1347, doi: 10.1016/S20953119(17)61826-4.

Zhang, Q., M.J. Li, B.B. Zhou, X.L. Li, J. Sun, J.K. Zhang, and Q.P. Wei. 2017. Multivariate analysis of relationship between soil nutrient factors and fruit quality characteristic of 'Fuji' apple in two dominant production regions of China. Chinese J. Appl. Ecol. 28:105-114, doi: 10.13287/j.1001-9332.201701.030.

Zhou, B.B., Q. Zhang, J. Sun, X.L. Li, and Q.P. Wei. 2016. Study and application of partial least-squares regression on relationship between soil nutrient and fruit quality. J. Fruit Sci. 33:106-112, doi: 10.13925/j.cnki.gsxb. 20150236.

Zhou, C., S.H. Lin, W.X. Li, and X.M. Zhou. 2002. Preliminary report on the Research of Main Environmental Factors Affecting the Formation of Apple Quality. Shanxi Fruits 2:5-7, doi: 10.3969/j.issn.1005-345X.2002.02.002.

Zhu, L., Z.X. Guo, H.C. Li, and L.S. Zhang. 2001. Analysis of climatic conditions affecting the quality of Fuji apple and climate division in Shaanxi province. Chinese J. Agrometeorol. 22:50-53, doi: 10.3969/j.issn.1000-6362.2001. 04.013 . 